\title{
Dynamic behavior of coal under true triaxial prestressed by using a Hopkinson bar
}

\author{
Shiwei Zhang ${ }^{1} \cdot$ Wen Wang ${ }^{1,2} \cdot$ Kai Liu $^{3} \cdot$ Shuang Gong ${ }^{1} \cdot$ Donngyin $\mathrm{Li}^{1} \cdot$ Huamin $\mathrm{Li}^{1}$
}

Received: 9 January 2021 / Accepted: 6 September 2021 / Published online: 30 September 2021

(C) The Author(s) 2021

\begin{abstract}
Deep mining is faced with severe rock dynamic problems. Coal bears high-strength static load in the deep and is prone to impact under the influence of dynamic load disturbance such as roof breaking. The true triaxial Hopkinson pressure bar system is used to conduct dynamic load impact tests on coal specimens under different triaxial prestressing forces to simulate the bearing characteristics of coal under different engineering conditions. The results show that the dynamic mechanical characteristics of coal are confinement-dependent under the same dynamic load, and the energy transmission of each component are significantly different, which is obviously different from that under static load; Furthermore, the influence range of intermediate principal stress on dynamic characteristics of coal specimen is 6 8 MPa. Based on the failure characteristics, the enhancement of the intermediate principal stress will increase the integrity and the internal damage of a coal specimen after failure; It should be noted that the strain signals obtained in the $Y / Z$ axis direction are mainly the response to the triaxial prestress, and the stress wave of coal specimen is mainly influenced in the impact direction. In underground coal mining, by changing the triaxial prestressed state of coal, the buffering effect of stress wave is improved, and the damage of coal caused by the impact is reduced.
\end{abstract}

Keywords Coal specimen · True triaxial Hopkinson bar $\cdot$ Static-dynamic coupled loads $\cdot$ Energy propagation $\cdot$ Failure modes

\section{Introduction}

Deep coal mining is in a three-dimensional stress environment of static-dynamic stress coupling loads owing to the influence of high crustal stress and strong mining disturbance, which compared with shallow mining (Qiao et al. 2014; Xie et al. 2019a, b; Ye et al. 2018; Zhang and Zhao 2014a). The deformation of coal seam can largely offset the influence of high static stress and dynamic impact, but the rapid deformation and accompanying energy instantaneous release of coal seam easily cause dynamic disasters such as coal bump (Zhao et al.

Responsible Editor: Zeynal Abiddin Erguler

Wen Wang

211802010014@home.hpu.edu.cn

1 School of Energy Science and Engineering, Henan Polytechnic University, Jiaozuo 454003, China

2 State Collaborative Innovation Center of Coal Work Safety and Clean-efficiency Utilization, Jiaozuo 454003, China

3 Department of Civil Engineering, Monash University, Melbourne, VIC 3800, Australia
2017, 2018a, b), which mechanical mechanism belongs to dynamic category (Li et al. 2008; Hokka et al. 2016). However, it should point that the present research on the coal dynamic behavior is limited to the uniaxial and conventional triaxial dynamic impact experiments by using SHPB, or the dynamic disturbance experiment in one direction with triaxial pressure is carried out by using the true triaxial equipment ( $\mathrm{Du}$ et al. 2016; Gu et al. 2018, 2019). Nevertheless, these investigations cannot describe the complex environment of threedimensional static-dynamic combination loads, which drives us to carry out mechanical experimental research with dynamic and triaxial static stress. Therefore, it is of great significance to reveal the dynamic impact and catastrophe mechanism of the coal seam in the procedure of deep mining

The failure process of coal and rock is a nontransient response at a finite rate. Strain rate is often used as the distinguishing criterion in rock tests (Ju et al. 2019; Zhang and Zhao 2013a). It is generally considered that the strain rate in underground engineering activities is in the range of $10^{2} \sim 10^{3} \mathrm{~s}^{-1}$ (Grady and Kipp 1979), and the dynamic properties of the rock are usually measured by various SHPB devices and some other deformation equipment. The experimental technology of Hopkinson pressure bar has been developed 
for more than 100 years, the experimental materials extend to polymers, composites, rocks, concrete, and foams, and the experimental methods are the uniaxial dynamic loads, uniaxial static-dynamic combination loading, and triaxial confining pre-stress static-dynamic combination loading ( $\mathrm{Hu}$ et al. 2014). Furthermore, a true triaxial Hopkinson bar system had developed, which can realize the multiaxial compression, tension, and shear tests (Liu et al. 2019, 2020; Xu et al. 2020).

Joints widely exist in natural rock mass such as coal, sandstone, and limestone (Li and Ma 2009; Li et al. 2019), and the mechanical behavior of coal is similar to that of other rocks, such as quasi-static mechanical properties and dynamic response of the sandstone and limestone (Zhu et al. 2019; Zhang and Zhao 2013b; Zhou et al. 2018; Zou et al. 2016). However, there are lots of cracks in the coal that have poor compactness (Feng et al. 2014), the uniaxial and triaxial static test showed that the bearing capacity of the coal seam is poor in the occurrence environment, and it is easy to deform and destroyed under the action of high stress (Wang et al. 2016). Also, the crack initiation and propagation toughness of coal, roof, and floor increase with the increase of loading rate and crack speed under static and dynamic combined load, resulting in the surface small pieces being ejected (Zhang and Zhao 2014b). The quasi-static triaxial compressive experiment of coal specimen shows that the strength increases with the increase of confining pressure prestress what confines the lateral deformation so that increases the elastic deformation range, the triaxial strength of coal increases with the increase of strain rate (Wang et al. 2016). Furthermore, the coal seam bearing the triaxial pre-stress will lose its stability under dynamic disturbance, which will destroy the original stress environment. Therefore, the coal seam will lose its stability rapidly under the static-dynamic coupled loading, which has a severe impact on the working space of underground mining activities. In addition, the dynamic strength of coal specimens under triaxial static-dynamic coupled loads is higher than that under uniaxial static-dynamic coupled loads, and the deformation and failure characteristics were also different (Wang et al. 2018, 2019a, b). The mechanical behaviors of the coal specimen under different loading are different in both static and dynamic tests. Therefore, it is of great significance to know the dynamic behavior of the coal specimen under the triaxial pre-stress and understand the bearing characteristics of the coal seam in a deep occurrence environment.

Based on the structural characteristics of rock, the deformation and failure processes are extremely complex and uncertain (Xie et al. 2011; Chen and Wang 2013). However, the dynamic or static strength of rock is essentially the energy variation, energy release is the internal logic of coal and rock failure suddenly in the micro-level. Also, the coal seam is in a dynamic equilibrium of energy in the original stress environment and equivalent swaps the energy exerted by the outside all long. When the energy exerted by the outside is greater than the coalbearing capacity, the coal unit will break through the deformation limit to release the energy of static energy and dynamic energy to the outside rapidly. From the viewpoint of microscopic, the stress wave destroying coal seam is the development of internal fracture, and at the macro level is the micro-cracks throughout each other, to local fracture and eventually to integral collapse (Xie et al. 2008). The dynamic disturbance of stress wave precipitates the internal structure damage of coal seam aggravated, the cracks expansion and instability failure in macro-level, which shows the energy transfer laws in the process of impact, bearing, and instability in micro-level.

Therefore, based on the references, the mechanical behaviors of coal were included the quasi-static uniaxial and triaxial compression, and dynamic-static uniaxial and conventional triaxial, and there were no reports to introduce the dynamic behaviors of coal under true triaxial prestress. Thus, in this experimental study, the influences of the triaxial pre-stress on the dynamic behaviors of coal specimens are analyzed by changing the intermediate principal stress with the same impact velocity and explain the test data. The variation characteristics of dynamic stress-strain curves and energy-time curves under different pre-stress states are analyzed and the response signal in the Y/Zaxis direction and failure characteristics of coal specimens are discussed. And the function of time and prestress in the process of coal seam crack formation is expounded. This study enriches the dynamic behaviors of coal under different pre-stress states and experimental equipment and provides the theoretical and technical basis of the pressure bump control in underground mining engineering.

\section{Experimental procedures}

\section{Specimen preparation}

The coal specimens were extracted from the same coal seam without visible geological discontinuities in Henan, China. The standard cubic specimen is $52 \times 52 \times 52 \mathrm{~mm}^{3}$ with elaborate preparation. The specimens with better integrity and homogeneity are selected to meet the requirements of the staticdynamic combined loading experiment (Zhou et al. 2012).

The environment is humidity in the coal mine underground, to simulate the underground environment, the selected coal specimens were placed on the platform in the sealed tank with water, the temperature and humidity in the sealed tank were kept at $25^{\circ} \mathrm{C}$ and the relative humidity was $60 \% \sim 70 \%$. Also, the weight of coal specimens was measured before and after treatment. The results show that the water content of the coal specimen is in the range of $1.47 \% \sim 1.53 \%$, with an average of $1.52 \%$. 


\section{True triaxial Hopkinson bar system}

The true triaxial Hopkinson pressure bar system developed at Monash University, which was used for this experimental study, can achieve the true triaxial pre-stress state and conduct for dynamic multiaxial of rocks, concrete, and coal (shown in Fig. 1)(Liu et al. 2019). At end of the X-axis direction, it is equipped with an impact energy buffer device, which is used to absorb the energy transmitted, and avoid the transmission energy reflect to affect the experiment results and cause damage to the equipment. In addition, the dynamic loads can be applied by launching a striker bar in the gas gun.

In this experiment, the specimen is not completely closed with the triaxial pre-stress loads. The collision and friction of the bars on the two intersecting dimensions are caused by the specimen deformation, which leads to the responder signal collected on the strain gage disordered and affects the test results. Therefore, the standard cubic specimen is $52 \times 52 \times 52$ $\mathrm{mm}^{3}$, which is $2 \mathrm{~mm}$ longer than the section side of the bar. The bars will be deformed due to the inevitable collision and friction between the contact surface of bars and specimen, there are metal gaskets between bars and specimen surface, which size and material are the same as those of the bars to diminish the error in the test process. Besides, the petrolatum was used to minimize the friction to reduce the influence of the end effect. In the process of impact loading, the dynamic response and damage evolution of the cubic coal specimen in six surfaces can be processed by the strain signal on each loading bar in the triaxial direction.

\section{Experimental scheme}

Coal is a kind of rock, nevertheless, its mechanical properties are quite different. In this study, the dynamic loads were applied by the gas pressure, which is $0.8 \mathrm{MPa}$. In addition, the pre-stress is $4.68 \%$ $45.11 \%$ of the peak uniaxial compressive strength that was applied to the coal specimen before the dynamic loading. The uniaxial compressive test results can be seen in Fig. 2.

Therefore, in the experimental scheme, the pre-stress in the $\mathrm{X}$ and $\mathrm{Z}$-axis are $8 \mathrm{MPa}$ and $6 \mathrm{MPa}$, respectively, and the prestress in the Y-axis are 2, 4, 6, 8, and $10 \mathrm{MPa}$, respectively. The strain rate of the experiment system was controlled in a small fluctuation range to reduce the error during the test.

\section{Date interpretation}

\section{Stress wave propagation}

According to the Hopkinson bar system, the dynamic applied by the preset air pressure to push the bullet to impact the incident bar, and the energy in the incident bar is transmitted to the specimen in the form of the wave, which is transferred to the contact surface and occur transmission and reflection. In the triaxial Hopkinson experiment system, not only is the energy transmitted to the specimen but also reflected the incident bar. The energy transferred from the specimen can be divided into two parts, one is to absorb by the specimen to failure, the other is to transmit and reflect along the transmitted bar and four output confined bars (shown in Fig. 3). The energy values during the experiment can be calculated by the strain signal collected on the six bars.

\section{Calculation methods}

The basic principle of the triaxial Hopkinson pressure bar is based on the "one-dimensional stress wave hypothesis in the bar" and "stress/strain homogenization hypothesis of specimen", which deems that the error between amplitude and time of stress wave is less than $3 \%$. In other words, the crosssection of the bar could keep the plane state, and the stress
Fig. 1 True triaxial Hopkinson pressure bar system (Liu et al. 2019)

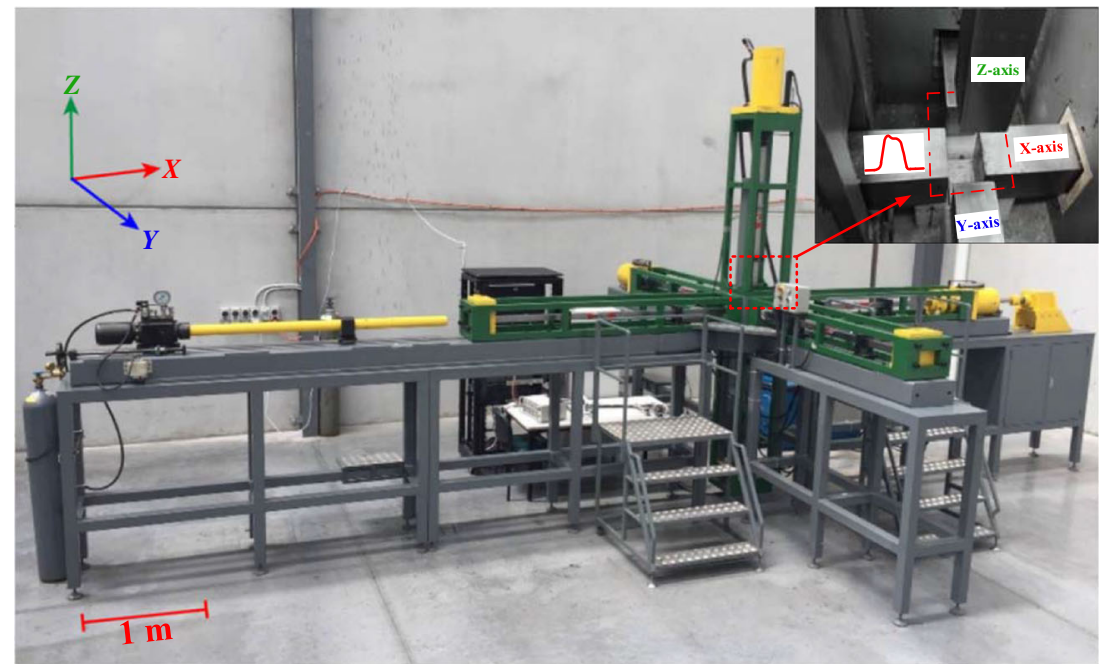




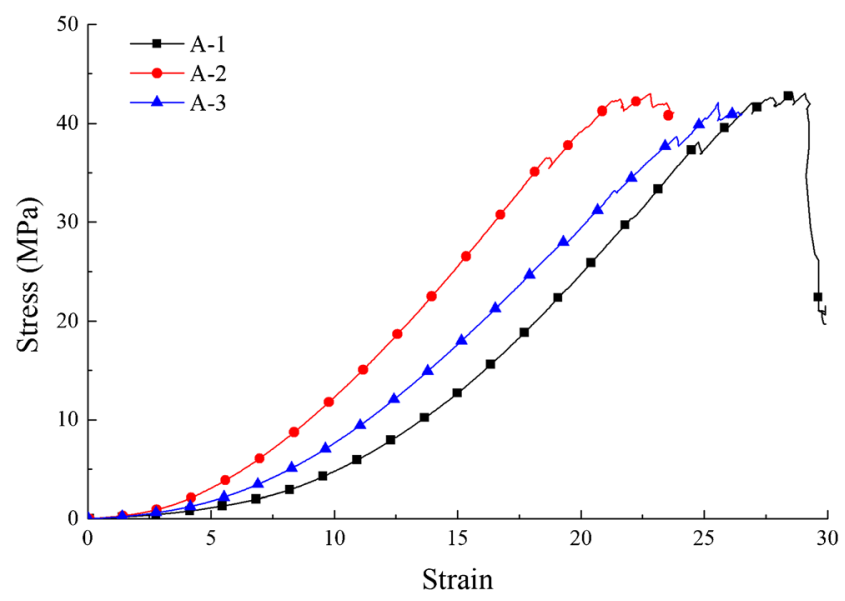

Fig. 2 Stress-strain curves of quasi-static uniaxial compressive test

equilibrium is well achieved of the square bar. Along the impact direction, the voltage signal obtained in the triaxial Hopkinson bar test was interpreted by the theory of the elastic one-dimensional stress wave propagation (Kolsky 1949, 1953). According to the "stress/strain homogenization hypothesis of specimen" (i.e., $\left.\varepsilon_{i n}(t)+\varepsilon_{r e}(t)=\varepsilon_{t r}(t)\right)$, the average stress $\sigma$, strain $\varepsilon$, and strain rate $\dot{\varepsilon}$ can be determined with the equations (Xu et al. 2020):

$$
\begin{aligned}
& \sigma_{x}(t)=\frac{P_{1}(t)+P_{2}(t)}{2 A_{s}}=\frac{E_{b} A_{b}}{2 A_{s}}\left[\varepsilon_{i n}(t)+\varepsilon_{r e}(t)+\varepsilon_{t r}(t)\right]=\frac{E_{b} A_{b}}{A_{s}} \varepsilon_{t r}(t) \\
& \dot{\varepsilon}(t)=\frac{V_{1}(t)-V_{2}(t)}{L}=\frac{C_{b}}{L}\left[\varepsilon_{\text {in }}(t)-\varepsilon_{r e}(t)-\varepsilon_{t r}(t)\right]=-\frac{2 C_{b}}{L} \varepsilon_{r e}(t) \\
& \varepsilon(t)=\int_{0}^{T} \dot{\varepsilon}(t) d t=\frac{C_{b}}{L} \int_{0}^{T}\left[\varepsilon_{i n}(t)-\varepsilon_{r e}(t)-\varepsilon_{t r}(t)\right] d t=-\frac{2 C_{b}}{L} \int_{0}^{T} \varepsilon_{\mathrm{re}}(t) d t
\end{aligned}
$$

The subscript 'in', 're', and 'tr' correspond to the incident, reflected, and transmitted waves in the impact direction,

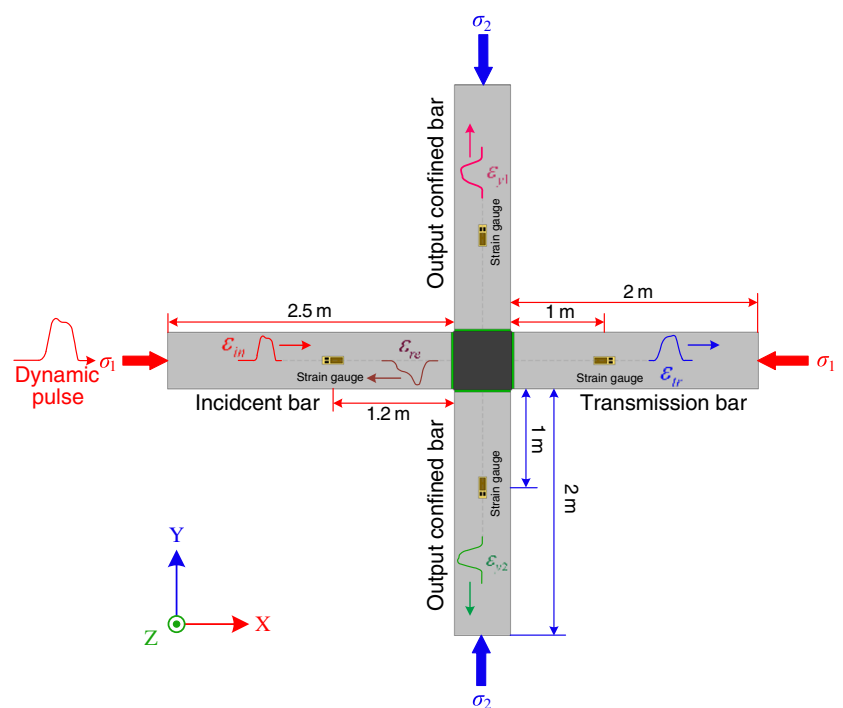

Fig. 3 Stress wave propagation in the triaxial Hopkinson bar (Liu et al. 2019) respectively. The stress and strain of the specimen in the $\mathrm{Y}$ and $\mathrm{Z}$ direction can be calculated by follows (Yang and Shim 2005):

$\sigma_{i}(t)=\frac{E_{b} A_{b}}{2 A_{s}}\left[\varepsilon_{i 1}(t)+\varepsilon_{i 2}(t)\right], i=y, z$
$\varepsilon_{i}(t)=\frac{C_{b}}{L} \int_{0}^{T}\left[\varepsilon_{i 1}(t)+\varepsilon_{i 2}(t)\right] d t, i=y, z$

where $\sigma_{i}(\mathrm{t})$ and $\varepsilon_{i}(\mathrm{t})$ are the stress and strain of specimen in the $\mathrm{Y}$ and $\mathrm{Z}$ directions, respectively.

Based on the energy conservation laws, each component of energy during the experiment can be determined by:

$E_{I}=\frac{A_{b}}{\rho_{b} C_{b}} \int_{0}^{T} \sigma_{i n}^{2}(t) d t$

$E_{R}=\frac{A_{b}}{\rho_{b} C_{b}} \int_{0}^{T} \sigma_{r e}^{2}(t) d t$

$E_{T_{i}}=\frac{A_{b}}{\rho_{b} C_{b}} \int_{0}^{T} \sigma_{t r}^{2}(t) d t, i=x, y, z$

where $\rho_{b}$ is the density of the specimen, $\sigma_{i n}(\mathrm{t}), \sigma_{r e}(\mathrm{t})$, and $\sigma_{t r}(\mathrm{t})$ are the dynamic stress of the incident, reflected, and transmission waves, respectively; $E_{I}, E_{R}$, and $E_{T}$ are the incident, reflected, and transmission energy, respectively.

The specimen was loaded in the elastic stage by the prestress in this experiment, which always in an equilibrium state so that the kinetic energy and nonmechanical energy have no change, and the external stress working is completely turned into the deformation potential energy of the specimen and stored in the specimen. In addition, one part of the dynamic stress is used to absorb to destroy the specimen, and the other part of which is transmitted and reflected. The deformation density $w_{s}$ of the specimen applied on axial pre-stress can be calculated by:

$w_{s}=\int \sigma_{i} d \varepsilon_{i}=\int_{0}^{\varepsilon} \sigma_{i}(t) d \varepsilon_{i}(t), i=x, y, z$

where $\sigma_{i}$ is the axial pressure on a point of triaxial direction of the specimen; $d \varepsilon_{i}$ is the deformation of the specimen under axial pressure at a point in the triaxial direction. The strain energy $E$ of the specimen under the axial pre-stress can be considered as the closed area formed by the total stressstrain curve and the strain axis in the uniaxial compressive experiment results, which can be calculated by:

$E_{s}=V_{s} w_{s}$

According to the uniaxial compressive test results (shown in Fig. 2), the static energy of the coal specimens under prestress loads of 2, 4, 6, 8, and $10 \mathrm{MPa}$ are $0.51,1.75,3.65,6.22$, and $9.53 \mathrm{~J}$, respectively.

In the analysis of the test results, the effective section sides of the specimen are the loaded sizes, and the influence of the 
redundant sizes on the test results is not considered. Therefore, it is considered as the reaction of the energy absorption and release of what fell off from the specimen edge. The energy generated by the specimen that the part on the axial or edge is ignored.

In the true triaxial Hopkinson bar system, the pre-stress applied in the axial direction is equilibrium on both ends of the specimen, so it is simplified to the plane problem that the microelements of the specimen are scaled in the triaxial direction. Therefore, the energy losses of the specimen deformation caused by the tangential stress are not considered during the calculation, only the energy absorbed, transmitted, and release in the process of impacts are considered.

The amount of incident energy and use less energy dissipation can be calculated by:

$E_{\text {in-total }}=V_{s} w_{s}+E_{I}$

$E_{\text {out-total }}=E_{R}+E_{T_{i}}, i=x, y, z$

And the amount of absorption energy of the specimen used to failure in the true triaxial static-dynamic coupled loading experiment can be calculated by:

$$
\begin{aligned}
E_{a} & =E_{\text {in-total }}-E_{\text {out-total }} \\
& =\left(V_{s} w_{s}+E_{I}\right)-\left(E_{R}+E_{T i}\right) \\
& =V_{s} \int_{0}^{\varepsilon} \sigma_{1} d \varepsilon_{1}+\frac{A_{b}}{\rho_{b} C_{b}} \int_{0}^{T} \sigma_{i n}^{2}(t) d t \\
& -\frac{A_{b}}{\rho_{b} C_{b}} \int_{0}^{T} \sigma_{r e}^{2}(t) d t-\frac{A_{b}}{\rho_{b} C_{b}} \int_{0}^{T} \sigma_{t r_{i}}^{2}(t) d t, i=x, y, z
\end{aligned}
$$

From the above formula, the absorbed energy of the specimen increases with the incident energy increasing under the energy of impacts with the constant pre-stress, and the absorbed energy increases along with the pre-stress increasing while the impact energy is constant. Considering the lithology and sizes of the coal specimen, it will failure rapidly with a larger dynamic load, and the energy release to the axial direction and edge part, which result in experiment error. Therefore, the energy absorbed by the coal specimen failure will show a decreasing trend while the axial pre-stress increases to a certain value.

\section{Loading paths}

Based on the experimental plan, the specimen was placed in the loading cell, which is right at the intersection point of the axis of six bars, and the specimen is subjected to a desired triaxial pre-stress condition by the hydraulic cylinders, then the dynamic loading applied by the striker bar on the front end of the incident bar. During the test, the loading path of static and dynamic stress can be seen from Fig. 4, and the loading rate is $\sim 10^{-4} \mathrm{GPa} / \mathrm{s}$, such as the stress state is $\sigma_{1}>\sigma_{2}>\sigma_{3}$ $\left(t_{1}>t_{2}>t_{3}\right)$, the prestress in three-axis were loaded at the same time and reach to the corresponding values in turns, and then the dynamic loading $\left(t_{4}\right)$ is applied after pre-stress load stabilization until coal specimen failure.

\section{Calculation example}

In the SHPB test, all the pre-stresses and impacts are compressive, the deformation characteristics of the coal specimen were compressive and failure, so the compression was defined as positive in this study. Figure 5a showed the stress signals in the $\mathrm{X}$ direction with the pre-stress state of $(8,2$, and 6$) \mathrm{MPa}$. The incident wave applied on the coal specimen what confined by the triaxial pre-stress forms impact compression, a part of the impact pulse returns along the incident bar, it means that the stress applied on the specimen becomes tensile so that the calculation result is negative based on the electrical signal obtained by the incident bar strain gage, and the stress baseline value of reflected wave is less than zero indicates that the prestress damage the coal specimen internal structure. Other parts propagate through the coal specimen along the transmission/ output confined bar and are absorbed by the wedge reaction device, and the electrical signals are obtained to calculate the stress. Figure $5 \mathrm{~b}$ shows that the dynamic pulse propagates along with the $\mathrm{X}$ direction damage the coal specimen microstructure, then the generated stress wave propagates along the $\mathrm{Y}$ and $\mathrm{Z}$ bars because of the coal specimen's Poisson effect, the relation between the dynamic stress and times are calculated by the equations and signals. During the dynamic loads applied on the coal specimen, destabilize the static energy so that the cracks develop greatly and then damaged under the internal and external energy coupled effect. The stress signals obtained on the bars are the responses of the specimen damage and energy transfer. Figure $5 \mathrm{c}$ shows the evolution of three principal stresses $\left(\sigma_{1}, \sigma_{2}\right.$, and $\left.\sigma_{3}\right)$ during the impact. The three principal stresses initiate from $(8,2$, and 6) $\mathrm{MPa}$ rise to the peak values (127.67, 22.91, and 29.60) MPa at the moment of coal specimen breakage. The time of three principal stresses rise to the peak point were different, which at $132 \mu$ s in $\mathrm{Y}$ and $\mathrm{Z}$ direction and at $178 \mu \mathrm{s}$ in $\mathrm{X}$ direction. During the impact, the stress wave propagating in the bar was equilibrium, the triaxial pre-stress applied on the coal specimen was loading to restrain the stress wave propagation. The static pre-stresses in the $\mathrm{Y}$ and $\mathrm{Z}$ direction $(2,6) \mathrm{MPa}$ were lower than that of the $\mathrm{X}$-axis direction, the dynamic pulse would break through the static load limit in the $\mathrm{Y}$ and $\mathrm{Z}$ direction at first to apply on the $\mathrm{Y}$ and $\mathrm{Z}$ direction of the coal specimen and then damaged.

Figure $5 \mathrm{~d}$ shows the dynamic stress equilibrium check between both ends of the coal specimen in the $\mathrm{X}$ direction in this study. Based on the theoretical analysis, the value of incident stress and reflected stress are positive and negative, respectively, and the transmission stress is equal to the sum of the incident and reflected stresses. The calculation results show that they are different and float up and down. Coal is a kind of 

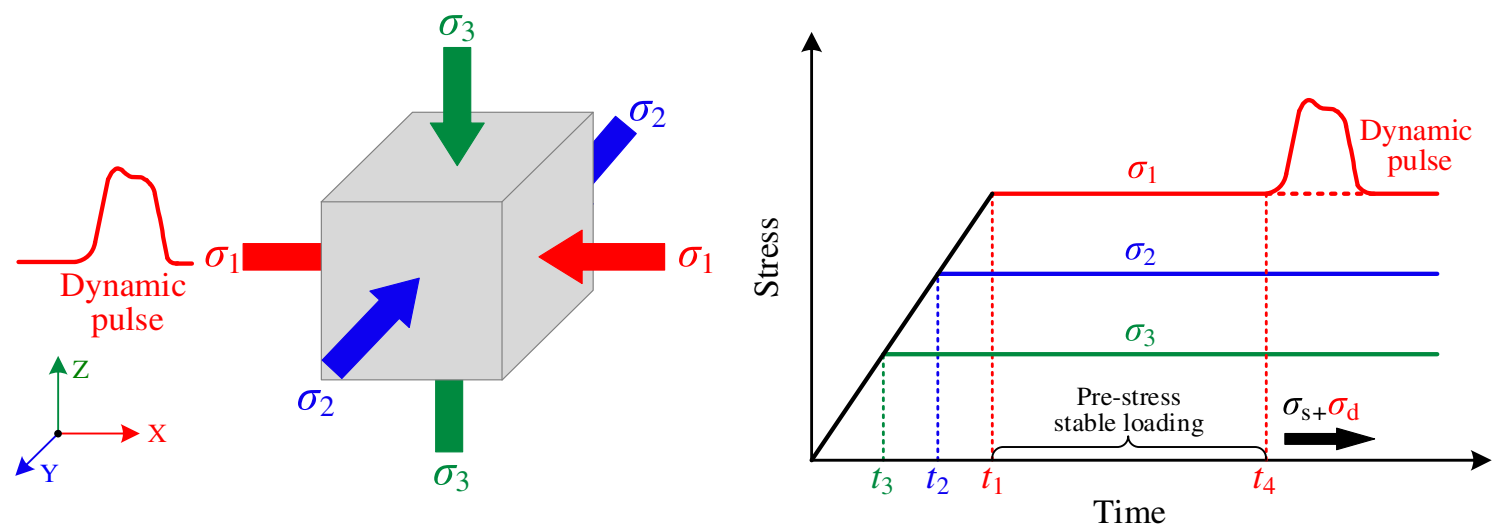

Fig. 4 Loading path of the triaxial static-dynamic in this experimental test (Liu et al. 2019)

soft rock; it is easier for coal specimens to accumulate static energy in the elastic range after applying the triaxial pre-stress. During the test, the dynamic pulse applied on the specimen break the balance of the triaxial pre-stress, and coal is easier deformation to bear the pressure than other hard materials. And the sum of incident and reflected stresses are sometimes higher than the transmission stress, the internal cracks of coal specimen were compressed by the triaxial pre-stress and resistance to deformation. Besides, the cracks influence the stress wave to transmit and cause the curves of incident+reflect and transmission wave to float up and down. In the SHPB test, it is generally believed that the stress wave satisfied the homogenization assumption in the specimen (Liu et al. 2019). The coal specimen can satisfy the stress equality between two ends

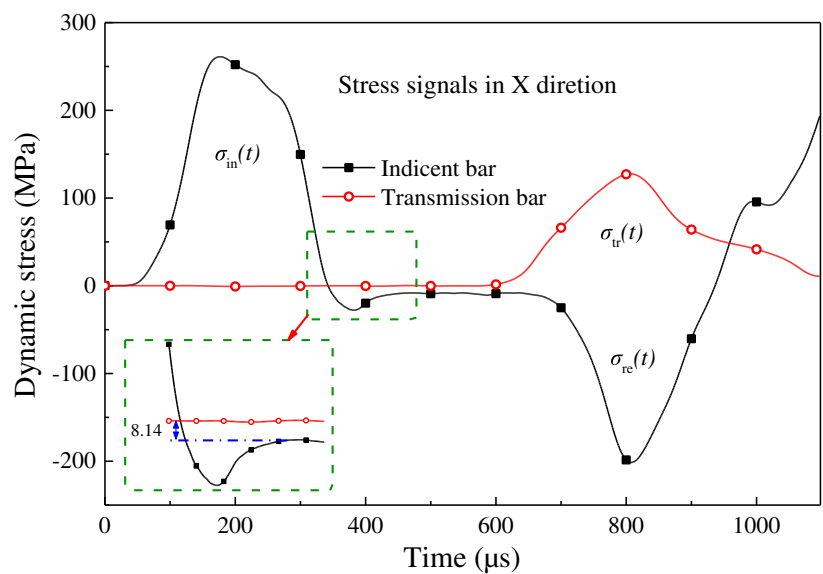

(a)

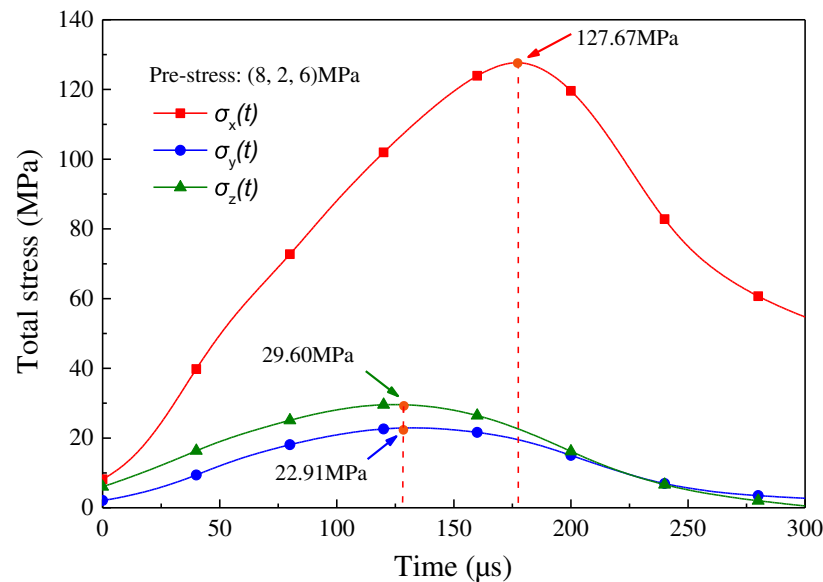

(c)

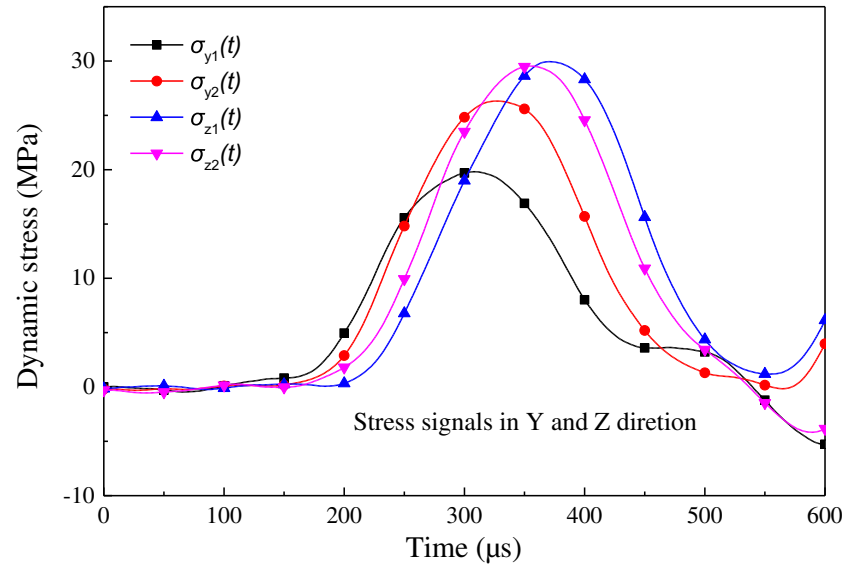

(b)

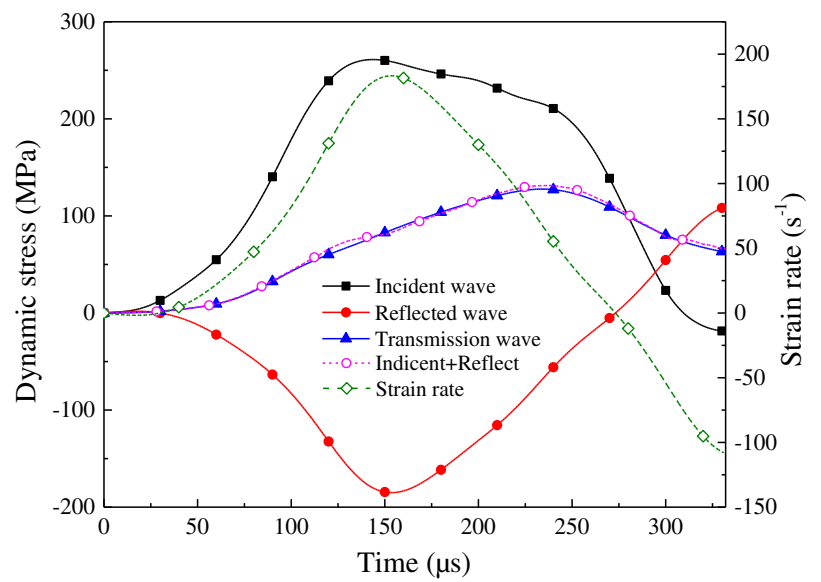

(d)

Fig. 5 The experimental data at the pre-stress condition (8,2, and 6) MPa and impact velocity of $16.80 \mathrm{~m} / \mathrm{s} ; \mathbf{a}$ stress signals in the X direction; b stress singles in $Y$ and $Z$ direction; $\mathbf{c}$ dynamic stress evolution; $\mathbf{d}$ dynamic stress equilibrium check 
in the true triaxial Hopkinson bar and ignore the effect of axial inertia. In addition, the petrolatum was used to minimize friction in this experiment.

\section{Test result}

\section{Dynamic strength}

According to the equations, the voltage signals were converted into the stress-strain and energy variation information in three directions (Wang et al. 2019a, 2019b). As the pre-stress of Y-axis increases, the peak dynamic stress of the coal specimen in the $\mathrm{X}$-axis direction are 127.67, 129.03, 138.10, 126.86, and 126.51 MPa, respectively; The peak dynamic stress in the $\mathrm{Y}$-axis direction are 22.91, 33.03, 32.51, 35.95, and $31.69 \mathrm{MPa}$, respectively; And the peak dynamic stress in Z-axis direction are 29.60, 33.16, 31.16, 29.84, and 34.56 $\mathrm{MPa}$, respectively.

Figure 6 presents the dynamic stress-strain curves of coal specimens in three directions at the pre-stress condition $\left(8,2\right.$, and 6) $\mathrm{MPa}$. In the X-axis, with the $\sigma_{2}$ increasing, the strain of the specimen after failure shows a decreasing trend in the whole, and the peak dynamic stress increases first and then decreases. The peak dynamic strength increased by $7.03 \%$ from $129.03 \mathrm{MPa}$ with triaxial pre-stress $(8,4$, and 6) $\mathrm{MPa}$ to $138.10 \mathrm{MPa}$ with $(8,6$, and 6) $\mathrm{MPa}$; when the triaxial pre-stress condition is from $(8,6$, and 6) $\mathrm{MPa}$ to $(8,8$, and 6) $\mathrm{MPa}$, the peak dynamic stress was decreased by $8.14 \%$, which is from 138.10 to 126.86 $\mathrm{MPa}$. The variation of dynamic stress-strain curves in the $\mathrm{Y}$ and $\mathrm{Z}$ are shown similarly. However, it shows a sudden increase and decreases when the $\sigma_{2}$ is in the range of $4 \sim 8$ $\mathrm{MPa}$, and the laws have some difference between the $\mathrm{Y}$ and $\mathrm{Z}$ direction. Therefore, it can be indicated that the influence range of the $\sigma_{2}$ on the dynamic stress of the coal specimen in this experiment is that the $\sigma_{1}$ and $\sigma_{3}$ are $8 \mathrm{MPa}$ and 6 $\mathrm{MPa}$, respectively, which the confinement state in three directions close to hydrostatic pressure $\left(\sigma_{1}=\sigma_{2}=\sigma_{3} \neq 0\right)$.

\section{Energy propagation}

To further investigate the influence of the $\sigma_{2}$ on the dynamic behavior at the micro-level, the energy in the whole impact test is calculated under different intermediate principal stress $\sigma_{2}$, and the energy variation laws of coal specimens with time are obtained in Fig. 6.

Figure 7 presents the variation curves of the energy-time under different intermediate principal stress $\sigma_{2}$ during the impact. The total energy calculated in the whole experimental system includes incident and static energy. The static energy is stored in it in advance and constant loading until coal specimen failure, and then unloaded. Form internal damage to instability and failure is the result of static-dynamic coupled loads, so the baseline of the energy absorption is the static energy. The $\sigma_{2}$ increased from 2 to $10 \mathrm{MPa}$, the difference of energy-time curves is mainly showed in the early stage and similar in the later stage in the process of impact. The variation characteristics of the energy-time curves with large difference parts are magnified and compared, which found that the difference mainly manifested in the variation characteristics between the incidents, absorbed and reflected energy with the different $\mathrm{Y}$-axis pre-stress, it is also the reason why the starting point of each component energy curves is different.

In the early stage of impact, the reflected energy is lower than incident energy at the $\sigma_{2}$ is 2,6 , and $10 \mathrm{MPa}$, the static energy is the baseline of absorbed energy, the absorbed energy increases with time, which indicates that the coal specimen is absorbing energy continuously and accumulating the dynamic energy, and shows the specimen continuously deforms in its elastic range. While the $\sigma_{2}$ is 4 and $8 \mathrm{MPa}$, the absorbed energy is negative after subtracting the static energy stored in the specimen, the curves of the reflected energy are closer to the incident energy than the other three $\mathrm{Y}$-axis pre-stress; The increasing trend of transmission energy in the $\mathrm{X}$ direction is relatively larger in these two loading states, and the static energy losses its original equilibrium state owing to the dynamic disturbance that makes the coal specimen to release part of the energy. The relationship of each component energy shows a similar law under all pre-stress loading conditions

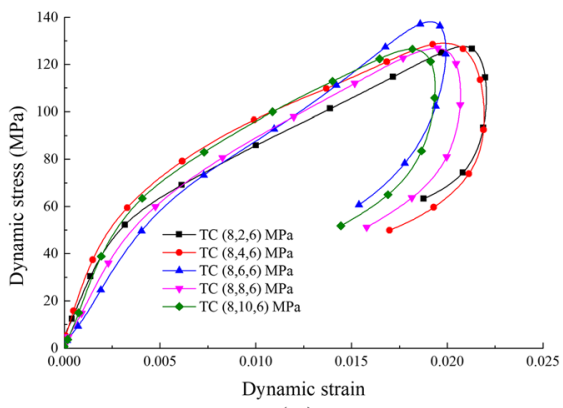

(a)

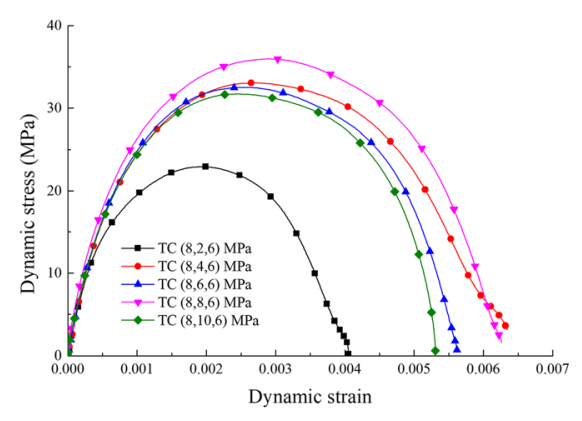

(b)

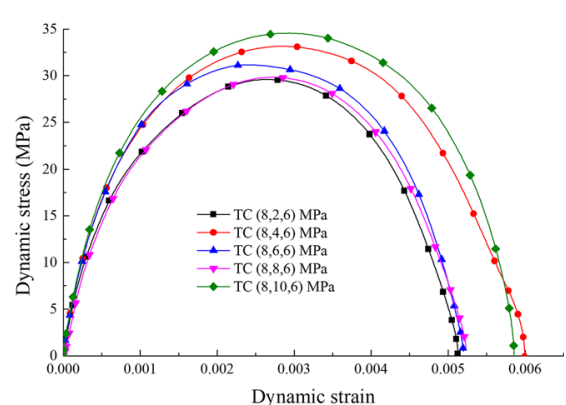

(c)

Fig. 6 Dynamic stress-strain curves of coal specimens. aX-axis direction; bY-axis direction; cZ-axis direction 


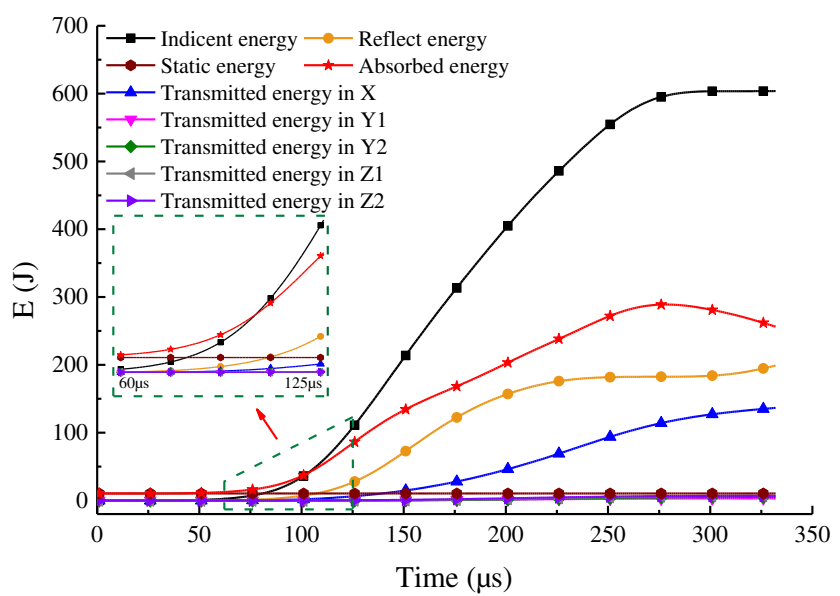

(a)

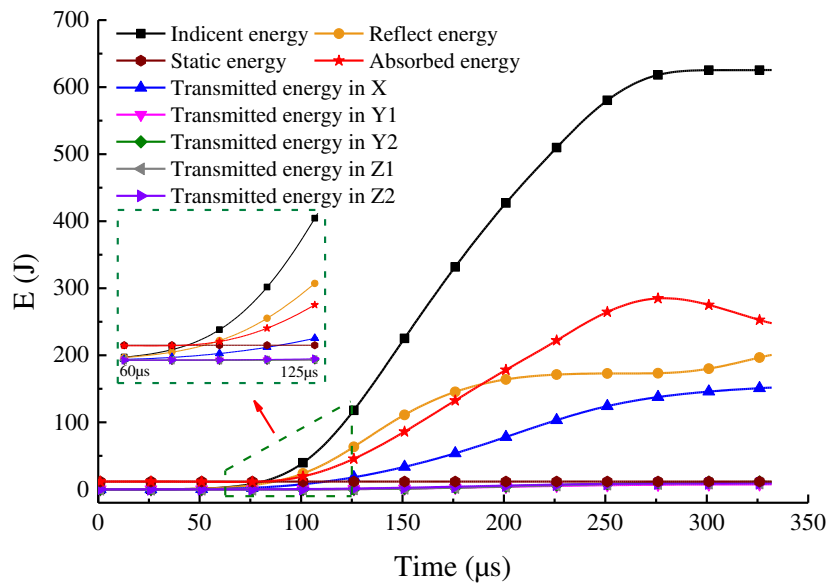

(b)

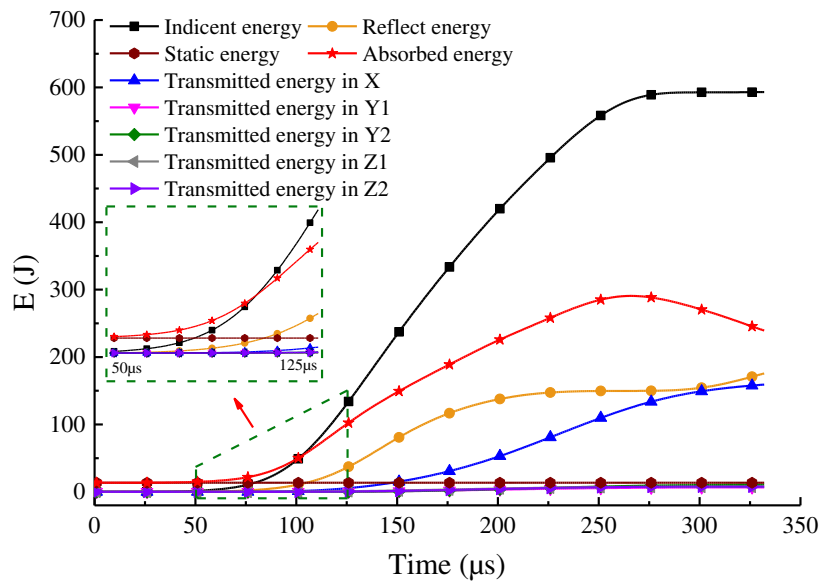

(c)

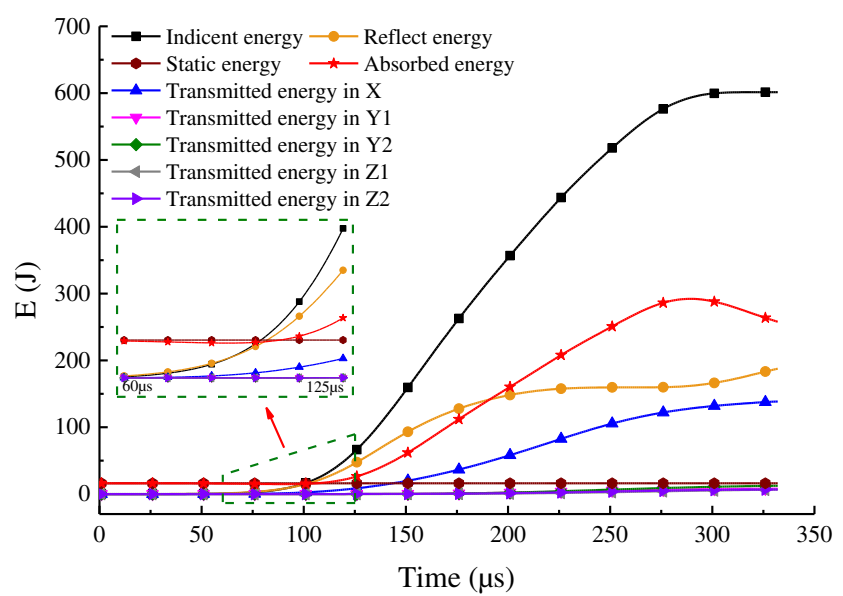

(d)

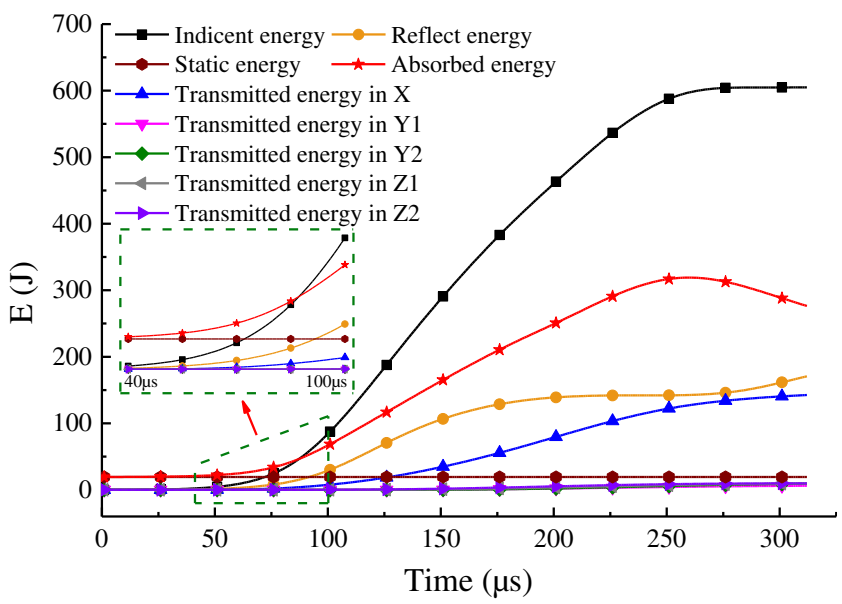

(e)

Fig. 7 Energy-time curve of the coal specimens with dynamic load (0.8MPa) in different static load condition. a (8, 2, and 6) MPa; b (8, 4, and 6) MPa; c $(8,6$, and 6$) \mathrm{MPa} ; \mathbf{d}(8,8$, and 6) $\mathrm{MPa} ; \mathbf{e}(8,10$, and 6) $\mathrm{MPa}$

after the incident energy reaches the peak. Nevertheless, the difference between the reflected energy and transmitted energy along the impact direction is decreases gradually with the $\mathrm{Y}$-axis pre-stress increasing. Although the difference increases with $8 \mathrm{MPa}$ of the $\mathrm{Y}$-axis pre-stress, the difference decreases with $10 \mathrm{MPa}$ of the $\mathrm{Y}$-axis pre-stress. In the relative case, the transmitted energy increases with the reflected energy decreasing in the impact direction. According to the analysis, the difference of the energy variation characteristics under the different $\mathrm{Y}$-axis pre-stress in the early or later stage of 
impact is owing to the confinement state of the coal specimen in triaxial directions.

\section{Transmitted energy in the $\mathrm{Y}$ and $\mathrm{Z}$ direction}

The strain signal in the $\mathrm{Y}$ and $\mathrm{Z}$ direction were obtained in the experiment. According to the dynamic strain-stress curves in the $\mathrm{Y}$ and $\mathrm{Z}$ direction, it can be seen that the variation of the curve is different from the strength characteristics, which shows deformation information and energy release during coal fracturing. Therefore, the properties of the stress, strain, and energy calculated by the signal on the output confined bars in the $\mathrm{Y}$ and $\mathrm{Z}$ direction during the test of staticdynamic combination loads, and explain the influence of the triaxial pre-stress that applied on the specimen.

The dynamic disturbance destroyed the energy equilibrium during the test. From Fig. 8, the difference between the incident energy and reflected energy is mainly in the early stage during impact, which indicates that part of the static energy transmitted along the incident bar as reflected energy, the transmitted energy mainly came from the dynamic loads in the $X$-direction. Therefore, the energy-time curves in the $Y$ and $\mathrm{Z}$ direction are drawn, compare the energy of $\mathrm{Y}$ and $\mathrm{Z}$ direction, and the total static energy to analyze and investigate the relationship and variation laws under different pre-stress of the $\mathrm{Y}$-axis direction.

The peak energy of the output confined bars is lower than the static energy under the different intermediate principal stress, which is the dynamic response in the directions. In Fig. 6, the peak value of energy in Y1 is higher than that in $\mathrm{Y}$, and the peak value of energy in $\mathrm{Z} 1$ is higher than that in Y2. The two ends of the same upward specimen are divided into loading and fixed, the Y1and Z1 bars are the loading ends, and the Y2 and Z2 bars are the fixed ends, which considered that the stress on both ends is uniform in the loading process. Newton's third law said the force is mutual, the fixed end is subjected to compressive stress at the loading end that passes through the specimen, and the pre-stress applied on both ends of the specimen is equal to that placed in the loading cell, but energy applied by the loading end that can drain energy, so the peak energy on the loading end is always higher than that of the fixed end.

As the pre-stress in the $\mathrm{Y}$-axis is gradually higher than that in the Z-axis, the peak value of energy in the Y-axis is gradually higher than that in the $Z$-axis, and the peak value of energy in the $\mathrm{Y}$-axis decreases when the loading state in the triaxial direction tends to be equal pressure. When the prestress of the $\mathrm{Y}$-axis is $10 \mathrm{MPa}$, the peak energy of the $\mathrm{Y}$-axis decreases gradually less than that of the $\mathrm{Z}$-axis and almost equals, and the peak energy in $\mathrm{Z} 1$ and $\mathrm{Z} 2$ bars remains unchanged. During the test, the energy in the $\mathrm{Y}$ and $\mathrm{Z}$ direction is always less than the total static energy. The stress wave destabilized the elastic energy balance of the coal specimen, which promotes the new and old cracks to develop and influence the static energy and gradually diffuses to $\mathrm{Y}$ and $\mathrm{Z}$ direction. The coal cannot continue to bear the dynamic energy within the deformation range, a small part of incident energy propagates to the $\mathrm{Y}$ and $\mathrm{Z}$ direction along with the static energy. Therefore, the signal measured on the lateral $\mathrm{Y}$ and $\mathrm{Z}$ bars is the feedback to the pre-stress, which shows the internal dynamic damage and cracks development of the coal specimen.

The pre-stress of $\mathrm{X}$-axis is the largest in triaxial direction, the stress wave will easier to break through the static balance in the $\mathrm{Y}$ and $\mathrm{Z}$ direction at first, and the energy of $\mathrm{Y}$ and $\mathrm{Z}$-axis are lower than the transmitted energy of $\mathrm{X}$-axis, so reaches to peak point earlier than that of the $\mathrm{X}$-axis. The dynamic stress shows the bearing characteristics of the coal specimen under the static-dynamic coupled loads, and the dynamic strain shows the deformation peculiarities in the triaxial direction. The dynamic stress and strain would decrease after reaching to peak, which indicates the yield and strain softening of coal specimen; The dynamic stress decreases and strain increases after reaching to peak in the $\mathrm{Y}$ and $\mathrm{Z}$ direction, which shows the cracks develop to damage and failure in the $\mathrm{Y}$ and $\mathrm{Z}$ direction. The dynamic stress reached to peak not means the energy is maximum, the internal structure was still destroyed by the stress wave after the coal specimen yield. The difference in size between the coal specimen and bars caused the kinetic energy loss is ignored, the incident energy has directionality and divergence along the impact direction, and has the weakening peculiarities after acting on the specimen. Therefore, the stress state of the coal seam can be improved to balance in the triaxial direction in the underground coal mining, increase its deformation performance and bear capacity to form a buffer effect, reduce the destruction of the coal seam caused by pressure bump.

\section{Failure modes}

The characteristics of the energy changing with time are the description of instability failure at the microscopic level. The development and propagation of surface cracks are the macroscopic failures that the stress wave applied to the microstructure of the coal specimen. The failure modes after the test are used to analyze the difference under different confinement states, which shows in Fig. 7.

According to the loading path, the microstructure variation is divided into two parts, one is the compression effect of static loads on the internal cracks; the other is the dynamic load applied by the cylindrical striker. The cracks' development and failure modes of the coal specimen after the test reflect the dynamic failure characteristics with the triaxial pre-stress. According to Fig. 9, the integrity of coal specimen after the dynamic test is gradually improved with the intermediate principal stress increasing, the reason why the coal specimen 


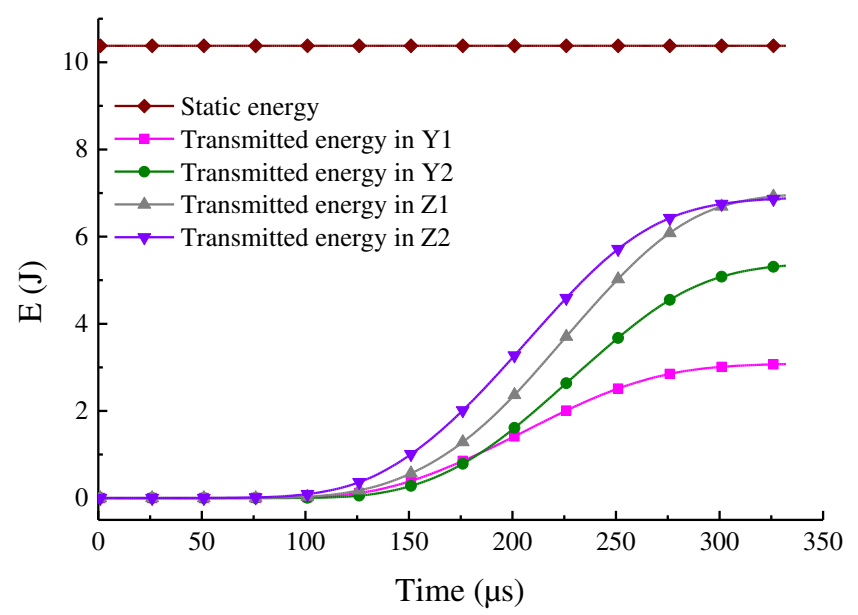

(a)

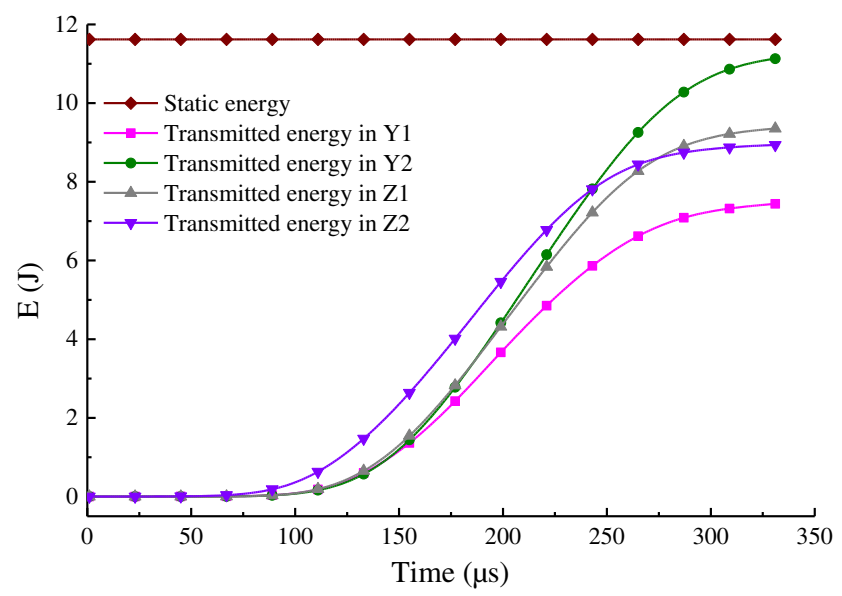

(b)

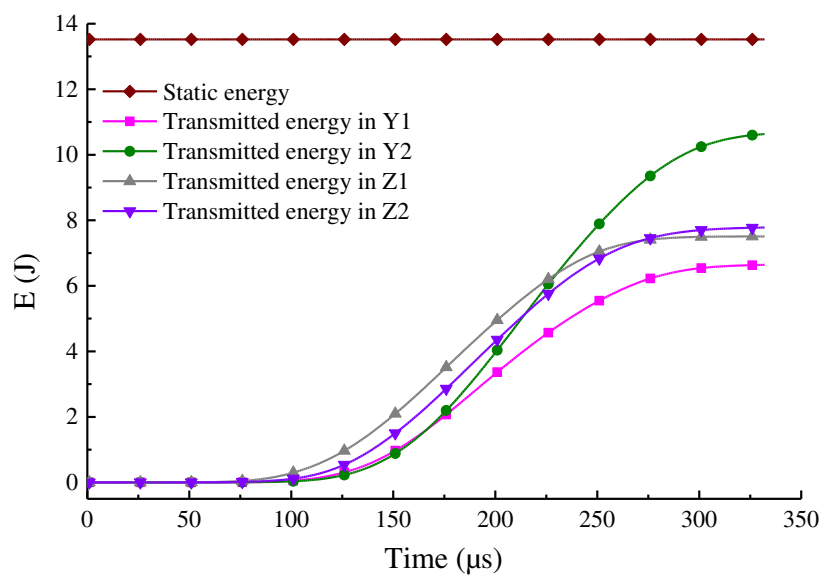

(c)

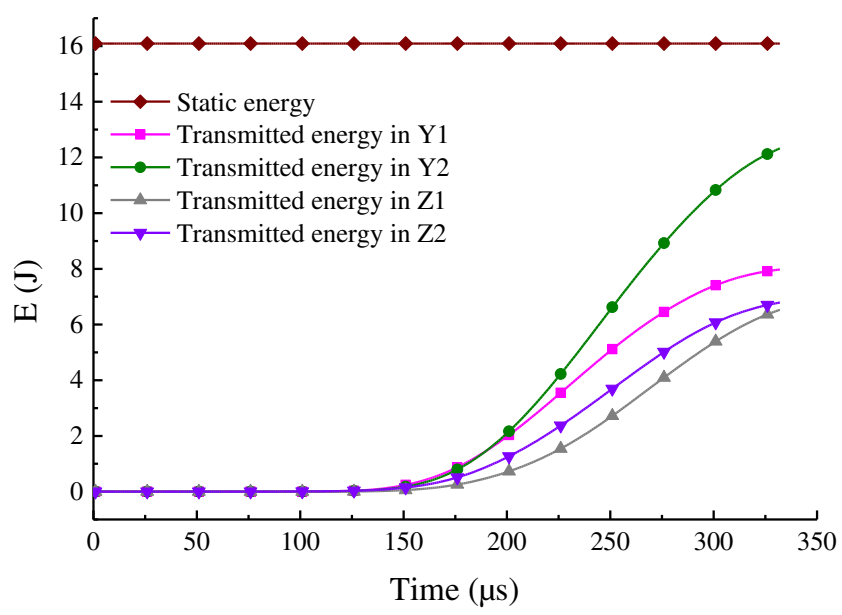

(d)

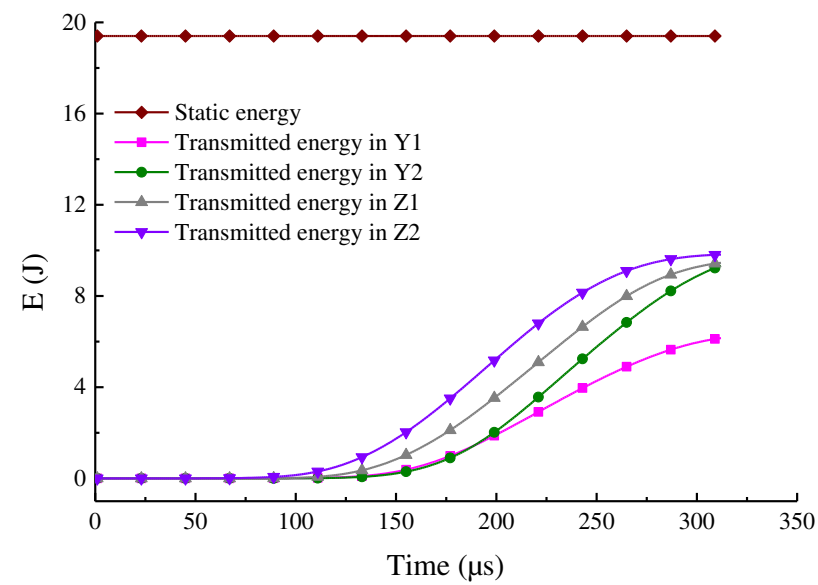

(e)

Fig. 8 The energy-time curve of the coal specimens in the Y/Z-axis direction with dynamic load $(0.8 \mathrm{MPa})$ in different static load condition. a (8, 2, and 6) $\mathrm{MPa} ; \mathbf{b}(8,4$, and 6) $\mathrm{MPa}$; $\mathbf{c}(8,6$, and 6) $\mathrm{MPa}$; d (8, 8, and 6) $\mathrm{MPa} ; \mathbf{e}(8,10$, and 6) $\mathrm{MPa}$

instability and failure are that the fractures of each surface are connected to form macro fracture zones. When the intermediate principal stress is $2 \mathrm{MPa}$, the fractures appeared on the coal specimen, which is parallel to the $\sigma_{2}$ and $\sigma_{3}$, and perpendicular to the $\sigma_{1}$ (impact direction), it breaks into two parts along the $\mathrm{Y}$ and $\mathrm{Z}$ direction; There are many slight through cracks in the specimen, which develop along the impact direction and lead to structural instability. Combined with the energy transfer 
characteristics of coal specimen (shown in Fig. 7), it is found that the energy absorbed by the dynamic loads is mainly used for damaging the internal structure in the early stage, and formed a macro fracture surface perpendicular to the impact direction. And the pre-stresses in the $Y / Z$ axis $(2,6) \mathrm{MPa}$ were lower than that of $\mathrm{X}$-axis direction ( $8 \mathrm{MPa}$ ), the restless energy would break through the static load limit in the $Y / Z$ axis at first, and the absorbed energy was used for the cracks developing, and the dynamic behaviors were different in different periods, which results in the phenomenon in Fig. 7. The edge structure of the specimen is seriously damaged and the integrity is poor while the intermediate principal stress increases to $4 \mathrm{MPa}$. And the surface cracks show central divergence and approximately parallel to the triaxial direction. Part of the structure is comminuted and obviously spallation, but still has integrity (shown in Fig. 9a). From the fracture surface, the development of the crack and interfingering are the main reasons for the coal specimen's lack of integrity. The coal specimen still maintains the integrity structure while the $\sigma_{2}$ is $6 \mathrm{MPa}$ and only the corner part is missing. The maximum angle between cracks and impact direction is $56^{\circ}$ (top view from vertical $\mathrm{Z}$ direction), the cracks are developed in parallel and interfingering and connected with each other on the adjacent interaction surface. When the $\sigma_{2}$ is $8 \mathrm{MPa}$, the maximum angle between cracks and impact direction is $32^{\circ}$ (top view from vertical $\mathrm{Z}$ direction). The macro penetrating cracks are developed on the active surface in the Y-axis direction, and the interface between specimen and incident bar is seriously damaged with the obvious development of the micro cracks. The integrity of the specimen is relatively complete, and there are few micro-cracks on the surface and more through cracks between adjacent surfaces (shown in Fig. 9c). When the $\sigma_{2}$ is $10 \mathrm{MPa}$, the maximum angle between cracks and impact direction is $100^{\circ}$ (top view from vertical $Z$ direction). The cracks parallel to the impact direction exist in the edge area, which belongs to the late formation. There is a damaged fracture zone parallel to the Y-axis in the middle of the surface, which is connected with the adjacent surface.

Therefore, the failure degree of the coal specimen is divided by the $\mathrm{Y}$-axis pre-stress of $6 \mathrm{MPa}$. When lower than $6 \mathrm{MPa}$,

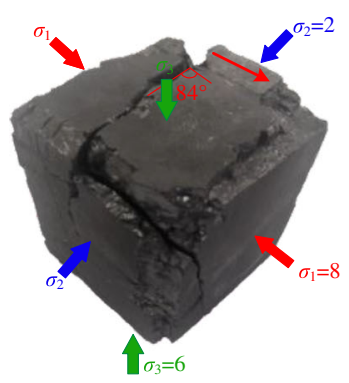

(a)

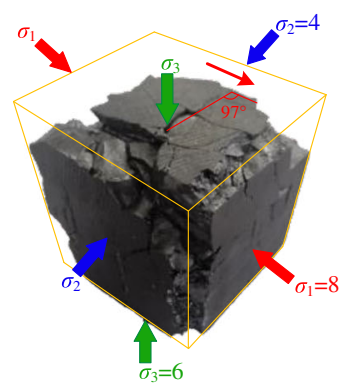

(b)

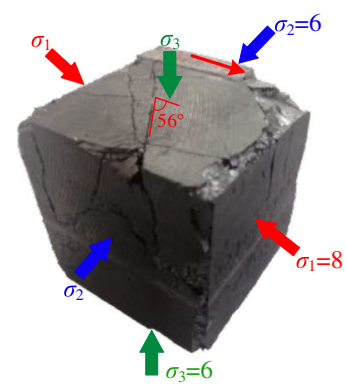

(c) the specimen will be seriously damaged with the intermediate principal stress increasing, the original integrity cannot be maintained, and the internal cracks were developed throughout and crisscross and damaged the structure larger. When between $6 \mathrm{MPa}$ and $10 \mathrm{MPa}$, the coal specimen could maintain the integrity, the main structural failure mode is a shear fracture, and the formed the angle between shear fracture and impact direction; the angle tends to decrease when $6 \mathrm{MPa} \leq \sigma_{2}$ $\leq 8 \mathrm{MPa}$; and the angle tends to increase when $8 \mathrm{MPa} \leq \sigma_{2} \leq 10$ $\mathrm{MPa}$, and it can be clearly observed the fracture pattern with ' $\mathrm{V}$ ' type. The changing trend of the angle between the shear fracture surface and the impact direction is closely related to the triaxial pre-stress state and dynamic loads. As the intermediate principal stress increases, the coal specimen can gradually maintain integrity. The triaxial pre-stress changes gradient will make more serious damage on the coal specimen (shown in Fig. 9a), the triaxial pre-stress close to hydrostatic pressure will be easier to bear the impact and maintain its integrity (shown in Fig. 9b, c), and when the $\sigma_{2}$ is higher than the $\sigma_{1}$ and $\sigma_{3}$, the coal specimen will be more likely to form internal damage and lose the stability.

\section{Discussion}

Coal is a kind of porous medium, which compactness is lower than that of sandstone and limestone. There are a lot of fractures and pores in the coal, which takes a long time to compressive the fractures in the uniaxial static test; The pre-stress is often required to be in the elastic range of coal specimen under the static-dynamic combination loads, although it is inevitable to compact the fractures in a certain extent, it does not cause damage to the internal structures of the coal specimens, nevertheless, the joints and fissures in coal specimen affect the stress wave propagation (Zou et al. 2019). From the dynamic stress-strain curves in the triaxial direction and the energy-time curves with different confinement states, the difference with other test results or regular variation is usually the triaxial pre-stress tend to balance $(8,8$, and 6$) \mathrm{MPa}$, or becomes gradient $(8,4$, and 6$) \mathrm{MPa}$. However, the cracks in the

Fig. 9 Failure modes of the specimens with dynamic load (0.8MPa) in different static load condition. a (8, 2, and 6) MPa; b $(8,4$, and 6) MPa; c $(8,6$, and 6) $\mathrm{MPa} ; \mathbf{d}(8,8$, and 6$)$; e $(8,10$, and 6$)$ 
coal specimen have experienced the stage of steady compression, rapid propagation, and transfixion of each other with the $\mathrm{Y}$-axis pre-stress increasing. The internal cracks of coal specimens are gradually compacted in the elastic range by changing the intermediate principal stress $\sigma_{2}$, the lateral deformation is limited by the triaxial pre-stress, and makes the dynamic strength increases gradually, the dynamic strength of coal sample increases with the $\sigma_{2}$ increasing. The influence of static load on the dynamic strength of coal samples is mainly in the elastic range, which is similar to the confining pressure. When the triaxial pre-stress increases to expansion and damage, the fractures increase, and dynamic strength decreases.

In this experiment, the specimens were treated to simulate the underground environment, and the water content of the specimen was in the range of $1.47 \% \sim 1.53 \%$ after the treatment. Furthermore, the water is attached to the surface of coal in the form of molecules, which affect the failure characteristics of the coal specimen. Therefore, the force between the water molecule and coal grain molecule should be considered, the mechanical modes can be seen in Fig. 10.

The interaction force has existed between the grains, they are the attractive force and repulsive force. Therefore, the attractive force and repulsive force between the water molecules, and between the water molecule and coal grain can be expressed by

$$
\begin{aligned}
& f_{w-c}=\frac{e_{w} \cdot e_{c}}{(R+r)^{2}} \\
& f_{w-w}=\frac{e_{w}^{2}}{(2 r+d)^{2}} \\
& f_{(w-c) c}=-\frac{b}{(R+r)^{n}} \\
& f_{(w-w) c}=-\frac{b}{(2 r+d)^{n}}
\end{aligned}
$$

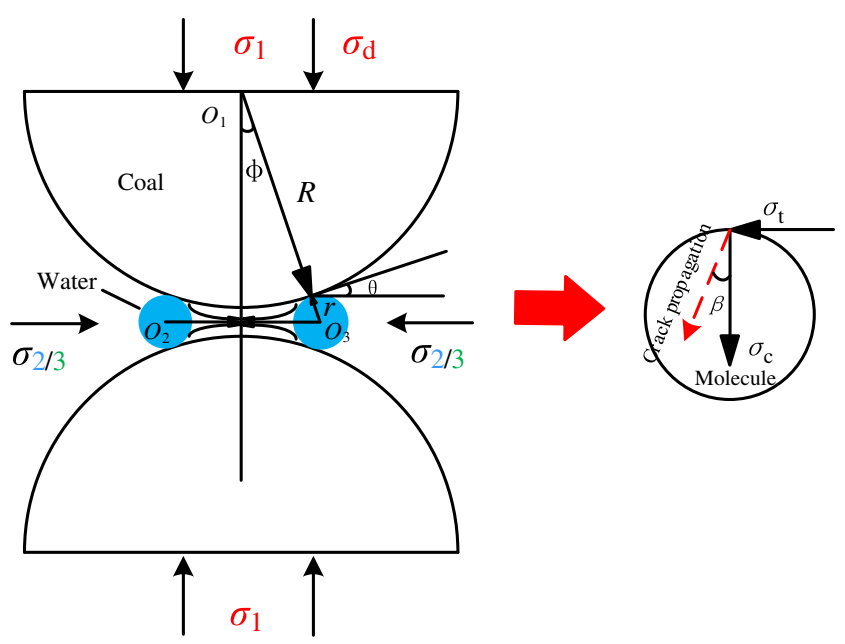

Fig. 10 Mechanical modes between molecules of water and coal grain where $f_{\mathrm{w}-\mathrm{c}}$ is the attractive force between the water molecules and coal grain, $f_{\mathrm{w}-\mathrm{w}}$ is the attractive force between the water molecules; $f_{(\mathrm{w}-\mathrm{c}) \mathrm{c}}$ is the repulsive force between the water molecules and coal grain, $f_{\mathrm{w}-\mathrm{w}}$ is the repulsive force between the water molecules; $e_{\mathrm{w}}$ and $e_{\mathrm{c}}$ are the charges of the ions, $R$ and $r$ are the radius of the coal grain and water molecules, $d$ is the distance between the adjacent water molecules, and $b$ is the proportional constant. Based on the mechanical characteristics in Fig. 10, the compressive strength $\sigma_{\mathrm{c}}$ and tensile strength $\sigma_{\mathrm{t}}$ of the water molecule and coal grains can be expressed:

$\sigma_{c}=\left(\sigma_{1}+\sigma_{d}\right) \cos \varphi+\sigma_{w-c}$

$\sigma_{t}=\left(\sigma_{2 / 3}+\sigma_{w-w}\right) \cos \theta$

where $\varphi$ is the stress action angle, $\theta$ is the contact angle, $\sigma_{\mathrm{w}-\mathrm{c}}$ is the superimposed stress of the attractive force and repulsive force between the water molecule and coal grain, and $\sigma_{\mathrm{w}-\mathrm{c}}$ is superimposed stress of the attractive force and repulsive force between the adjacent water molecules. In addition, the setting compressive strength of the molecules is $\sigma_{\mathrm{cl}}$, and the tensile strength of the molecules is $\sigma_{\mathrm{t} 1}$, the coal specimen failure means the $\sigma_{\mathrm{c}}>\sigma_{\mathrm{c} 1}$ and $\sigma_{\mathrm{t}}>\sigma_{\mathrm{t} 1}$. Also, the values of the $\sigma_{\mathrm{c}}$ and $\sigma_{\mathrm{t}}$ are determined the direction of the cracks, in other words, the main reason for the different propagation characteristics of the fractures (shown in Fig. 9) is that the different triaxial prestress.

Based on the dynamic stress-strain curves, it can be found that although the coal specimen also experienced the compaction stage in the early impact, the process is short-lived, and then the coal specimens showed the phenomenon of resistance to the dynamic loads (Li et al. 2016). There were no new cracks after compaction and showed resist failure with small deformation, we call it the support stage. Then, the coal specimen is generated a new fractures under the stress wave and expand stably, in order to bear the dynamic loads without damage, the coal specimen begins to deform as a whole, the deformation is used to buffer the stress wave to slow down the failure, that is, the elastic stage. With the stress wave gradually acting on the coal specimen, the internal fractures expand rapidly and the number of it begins to increase sharply, the deformation of the coal specimen can no longer bear the stress wave; The primary fractures reappeared and run through new cracks, internal cracks suffered irreversible damage and gradually lost its strength effect, which entered the yield stage and reached the peak dynamic stress that can be carried. After the impact test, although the specimen could keep the original shape, the internal structure has been damaged and unstable, which only showed the integrity on the macro level. Although the coal specimen was a failure, it still had residual strength even though the internal structure has suffered damage, which is the strain-softening stage. 
The energy-time curves are also corresponding to the dynamic stress-strain curves. The variation of the absorbed energy in the early stage of impact shows the characteristics of crack compaction and deformation resistance; the absorbed energy increased gradually with the time going, which is mainly used for the formation of new cracks and reemergence of the primary cracks in the coal. When the absorbed energy and transmitted energy along the impact direction increased steadily and the growth trend of reflected energy gradually slowed down, it shows that the old and new fractures in the specimen penetrated under the static-dynamic coupled loads, causing damage to the internal structure and losing the original strength effect. When the incident energy reached the peak value and no longer increased, the absorbed energy decreased, the reflected energy increased again and the transmitted energy tended to be stable gradually, the sample has been damaged, the energy that damage the coal specimen reflected along the incident bar owing to the triaxial prestress. In addition, according to the Griffith theory, when the effective stress at the crack tip reaches the energy that forms a new crack, the original cracks would be developed, and then the rock/coal failure.

The dynamic behavior is sensitive to the confinement condition of triaxial pre-stress in this experimental study. Based on the change laws of the peak dynamic stress in the impact direction, it shows that the triaxial pre-stress restrains the development of the crack, therefore, it is helpful to increase the dynamic strength by applying appropriate triaxial pre-stress. The energy variation with time reflected the behavior characteristics of the microstructure, the reaction of coal specimen to energy is different with different loading states, which mainly in the early stage of impact. It is easier to reflect the energy when the triaxial pre-stress close to the $\sigma_{1}$. Also, the signals in the $\mathrm{Y}$ and $\mathrm{Z}$ direction are the response to the triaxial pre-stress, including the deformation information and cracks development and energy release during coal specimen fracturing, and the failure mode is also restrained by the confinement what shows different failure degrees.

\section{Conclusions}

The dynamic behaviors of coal under the triaxial pre-stress were studied by using the true triaxial SHPB system. However, this study was only the preliminary exploration for the dynamic behaviors of coal specimens under the true triaxial static loads, the prestress in the $\mathrm{Y}$-axis was only changed to investigate the influence of triaxial prestress state on the dynamic behaviors of coal specimens. Therefore, there are many factors considered in our further works, such as water content and the direction of cleats. According to the strain signal obtained by the strain gages in this experimental system, the dynamic stress-strain curve in the triaxial direction and the energy-time values and curves were calculated and drawn. The variation characteristics of the dynamic behavior for the coal specimens were analyzed and discussed. The main conclusions are as following:

The coal specimen can satisfy the stress equality between two ends in the true triaxial Hopkinson bar and ignore the effect of axial inertia. In this experiment, the influence range of the $\sigma_{2}$ on dynamic strength is $6 \sim 8 \mathrm{MPa}$, which is close to the hydrostatic pressure loading state. Based on the dynamic stress-strain curves, although the dynamic strength is dependent on confinements, it has a great difference from the results of the conventional triaxial SHPB test, and the specimen resists the deformation after cracks compaction in the early impact stage, called the support stage.

The absorbed energy of the coal specimen includes static energy, the static energy formed elastic energy that stored in the specimen. The change laws of the energy-time curves show the difference is mainly in the early stage of impact. The strain signal in the $\mathrm{Y}$ and $\mathrm{Z}$ direction is the dynamic response of the triaxial pre-stress, provides the deformation, damage, fracture, and energy variation information, which is similar to the transmitted energy in the X-direction. The energy-time curves, dynamic stress-strain curves, and failure modes have corresponded, energy variation is the dynamic bearing characteristics of coal specimen in the microstructure.

The instability and failure of coal specimens are the macro manifestations of crack development and energy variation. With the intermediate principal stress increasing, the coal specimen can gradually maintain a complete shape after failure. Also, the failure is mainly caused by the shear force, and the cracks connect each other between the adjacent surfaces. The ' $\mathrm{V}$ ' type of fracture pattern is observed, and the failure modes dependent on the triaxial confinement state. Also, the triaxial pre-stress changes gradient will make more serious damage, and the triaxial pre-stress close to hydrostatic pressure will be easier to bear the impact and maintain the complete shape after failure, based on the distribution of the cracks on the failure surface, the internal structure has great damage.

Considering the force between the water molecule and coal grain molecule, there are two kinds of force between the molecules, which include attractive force and repulsive force. Also, based on the mechanical analysis, there are the compressive strength $\sigma_{\mathrm{c}}$ and tensile strength $\sigma_{\mathrm{t}}$ on the particle, the distance between the particles decreases under the prestress loads, which affect the includes attractive force and repulsive force. Therefore, the tensile strength $\sigma_{\mathrm{t}}$ increases with the prestress increasing in the $\mathrm{Y}$-axis, this is also the main reason for the different angles and lengths of the cracks after the test.

Acknowledgements We would like to thank Dr. Jian Zhao and Dr. Qianbing Zhang for helping with the experiment. The work was supported by the National Natural Science Foundation of China (51604093), 
National Key R\&D Program of China (2018YFC0604502), Key Teachers Project of Henan province (2019GGJS053), the Doctoral Research Fund Project of Henan Polytechnic University, China (B2017-42), and the Key Scientific Research Project Fund of Colleges and Universities of Henan Province (21A610005)

Data availability The data used to support the findings of this study are available upon request.

\section{Declarations}

Conflicts of interest The authors declare that we have no conflicts of interest in this work.

Open Access This article is licensed under a Creative Commons Attribution 4.0 International License, which permits use, sharing, adaptation, distribution and reproduction in any medium or format, as long as you give appropriate credit to the original author(s) and the source, provide a link to the Creative Commons licence, and indicate if changes were made. The images or other third party material in this article are included in the article's Creative Commons licence, unless indicated otherwise in a credit line to the material. If material is not included in the article's Creative Commons licence and your intended use is not permitted by statutory regulation or exceeds the permitted use, you will need to obtain permission directly from the copyright holder. To view a copy of this licence, visit http://creativecommons.org/licenses/by/4.0/.

\section{References}

Chen XG, Wang Y (2013) Energy dissipation and release during rock burst. Disaster Advances 6(09):48-54

Du K, Tao M, Li XB, Zhou J (2016) Experimental study of slabbing and rockburst induced by true-triaxial unloading and local dynamic disturbance. Rock Mechanics and Rock Engineering 49(09):34373453

Feng YY, Jiang CF, Liu DJ, Chu W (2014) Microstructure and its influence on $\mathrm{CH} 4$ adsorption behavior of deep coal. Chinese Physics B 23(02):7

Grady DE, Kipp ME (1979) The micromechanics of impact fracture of rock. International Journal of Rock Mechanics and Mining Sciences \& Geomechanics Abstracts 16:293-302

Gu HL, Tao M, Wang JX, Jiang HB, Li QY, Wang W (2018) Influence of water content on dynamic mechanical properties of coal. Geomechanics and Engineering 16(01):85-95

Gu HL, Tao M, Li XB, Momeni A, Cao WZ (2019) The effects of water content and external incident energy on coal dynamic behaviour. International Journal of Rock Mechanics and Mining Sciences $123: 16$

Hokka M, Black J, Tkalich D, Fourmeau M, Kane A, Hoang NH, Li CC, Chen WW, Kuokkala VT (2016) Effects of strain rate and confining pressure on the compressive behavior of Kuru granite. International Journal of Impact Engineering 91:183-193

Hu SS, Wang LL, Song L, Zhang L (2014) Review of the development of Hopkinson pressure bar technique in China. Explosion and shock waves 34(06):641-657

Ju MH, Li JC, Yao QL, Li XF, Zhao J (2019) Rate effect on crack propagation measurement results with crack propagation gauge, digital image correlation, and visual methods. Engineering Fracture Mechanics 219:14

Kolsky H (1949) An investigation of the mechanical properties of materials at very high rates of loading. Proc Phys Soc 62:676-700

Kolsky H (1953) Stress wave in solids. Clarendon Press, Oxford
Li JC, Ma GW (2009) Experimental study of stress wave propagation across a filled rock joint. International Journal of Rock Mechanics and Mining Sciences 45(3):471-478

Li XB, Zhou ZL, Lok TS, Hong L, Yin TB (2008) Innovative testing technique of rock subjected to coupled static and dynamic loads. International Journal of Rock Mechanics and Mining Sciences 45(05):739-748

Li JC, Zhao XB, Li HB, Chai SB, Zhao QH (2016) Analytical study for stress wave interaction with rock joints having unequally close-open behavior. Rock Mechanics and Rock Engineering 49(8):3155-3164

Li JC, Rong LF, Li HB, Hong SN (2019) An SHPB test study on stress wave energy attenuation in jointed rock masses. Rock Mechanics and Rock Engineering 52(2):403-420

Liu K, Zhang QB, Wu G, Li JC, Zhao J (2019) Dynamic mechanical and fracture behaviour of sandstone under multiaxial loads using a triaxial hopkinson bar. Rock Mechanics and Rock Engineering 52(07):2175-2195

Liu K, Zhao J, Wu G, Maksimenko A, Haque A, Zhang QB (2020) Dynamic strength and failure modes of sandstone under biaxial compression. International Journal of Rock Mechanics and Mining Sciences 128:23

Qiao W, Li WP, Zhang X (2014) Characteristic of water chemistry and hydrodynamics of deep karst and its influence on deep coal mining. Arabian Journal of Geosciences 7(04):1261-1275

Wang W, Li HM, Yuan RF, Gu HL, Wang C, Li HG (2016) Micromechanics analysis and mechanical characteristics of watersaturated coal samples under coupled static-dynamic loads. Journal of China Coal Society 41(03):611-617

Wang W, Wang H, Li DY, Li HM, Liu ZM (2018) Strength and failure characteristics of natural and water-saturated coal specimens under static and dynamic loads. Shock and Vibration 2018(PT.4):1-15

Wang W, Zhang SW, Li HM, Gong S, Liu ZM (2019a) Analysis of the dynamic impact mechanical characteristics of prestressed saturated fractured coal and rock. Advances in Civil Engineering 2019(PT.1): $1-10$

Wang W, Zhang SW, Liu K, Wang S, Li DY, Li HM (2019b) Experimental study on dynamic strength characteristics of watersaturated coal under true triaxial static-dynamic combination loadings. Chinese Journal of Rock Mechanics and Engineering 38(10): 2010-2020

Xie HP, Ju Y, Li LY, Peng RD (2008) Energy mechanism of deformation and failure of rock masses. Chinese Journal of Rock Mechanics and Engineering 09:1729-1740

Xie HP, Li LY, Ju Y, Peng RD, Yang YM (2011) Energy analysis for damage and catastrophic failure of rocks. Science ChinaTechnological Sciences 54:199-209

Xie HP, Gao MZ, Zhang R, Peng GY, Wang WY, Li AQ (2019a) Study on the mechanical properties and mechanical response of coal mining at $1000 \mathrm{~m}$ or deeper. Rock Mechanics and Rock Engineering 52(05): $1475-1490$

Xie H, Konietzky H, Zhou HW (2019b) Special Issue "Deep Mining". Rock Mechanics and Rock Engineering 52(05):1415-1416

Xu SL, Shan JF, Zhang L, Zhou LJ, Gao GF, Hu SS, Wang PF (2020) Dynamic compression behaviors of concrete under true triaxial confinement: An experimental technique. Mechanics of Materials 140: 18

Yang LM, Shim VPW (2005) An analysis of stress uniformity in split Hopkinson bar test specimens. International Journal of Impact Engineering 31(02): 129-150

Ye Q, Wang G, Jia ZZ, Zheng CS, Wang WJ (2018) Similarity simulation of mining-crack-evolution characteristics of overburden strata in deep coal mining with large dip. Journal of Petroleum Science and Engineering 165:477-487

Zhang QB, Zhao J (2013a) Effect of loading rate on fracture toughness and failure micromechanisms in marble. Engineering Fracture Mechanics 102:288-309 
Zhang QB, Zhao J (2013b) Determination of mechanical properties and full-field strain measurements of rock material under dynamic loads. International Journal of Rock Mechanics and Mining Sciences 60: 423-439

Zhang QB, Zhao J (2014a) A review of dynamic experimental techniques and mechanical behaviour of rock materials. Rock Mechanics and Rock Engineering 47(04):1411-1478

Zhang QB, Zhao J (2014b) Quasi-static and dynamic fracture behaviour of rock materials: phenomena and mechanisms. International Journal of Fracture 189(01):1-32

Zhao TB, Guo WY, Tan YL, Yu FH, Huang B, Zhang LS (2017) Failure mechanism of layer-crack rock models with different vertical fissure geometric configurations under uniaxial compression. Advances in Mechanical Engineering 9(11):15

Zhao TB, Guo WY, Tan YL, Lu FH, Wang CW (2018a) Case histories of rock bursts under complicated geological conditions. Bulletin of Engineering Geology and the Environment 77(04):1529-1545

Zhao TB, Guo WY, Tan YL, Yin YC, Cai LS, Pan JF (2018b) Case studies of rock bursts under complicated geological conditions during multi-seam mining at a depth of $800 \mathrm{~m}$. Rock Mechanics and Rock Engineering 51(05):1539-1564

Zhou YX, Xia K, Li XB, Li HB, Ma GW, Zhao J, Zhou ZL, Dai F (2012) Suggested methods for determining the dynamic strength parameters and mode-I fracture toughness of rock materials. International Journal of Rock Mechanics and Mining Sciences 49:105-112

Zhou ZL, Cai X, Ma D, Cao WZ, Chen L, Zhou J (2018) Effects of water content on fracture and mechanical behavior of sandstone with a low clay mineral content. Engineering Fracture Mechanics 193:47-65

Zhu QQ, Li DY, Han ZY, Li XB, Zhou ZL (2019) Mechanical properties and fracture evolution of sandstone specimens containing different inclusions under uniaxial compression. International Journal of Rock Mechanics and Mining Sciences 115:33-47

Zou F, Fang ZF, Xia MY (2016) Study on dynamic mechanical properties of limestone under uniaxial impact compressive loads. Mathematical Problems in Engineering 2016:11-11

Zou Y, Li JC, Zhao J (2019) A novel experimental method to investigate the seismic response of rock joints under obliquely incident wave. Rock Mechanics and Rock Engineering 52(09):3459-3466 